\title{
The cardiovascular reserve index (CVRI) - a surrogate index in predicting heat tolerance
}

\author{
Yoram Epstein*, Savyon Mazgaoker, Danit Atias, Ran Yanovich, Uri Gabbay, Yuval Heled \\ From 15th International Conference on Environmental Ergonomics (ICEE XV) \\ Portsmouth, UK. 28 June - 3 July 2015
}

\section{Introduction}

Cardiovascular Reserve Index (CVRI) was developed as a diagnostic method for estimating quantitatively cardiovascular performance reserve [1]. It has been also been suggested in previous studies as a predictor of cardiovascular related morbidities (e.g. shock or heart failure). We aimed to investigate the CVRI ability to distinguish between heat tolerant (HT) and heat intolerant (HI) individuals during exertional heat stress.

\section{Methods}

A modified version of the index was used in the present study as follows:

$$
\mathrm{CVRI}=100 \cdot(\mathrm{MAP}-\mathrm{CVP}) \cdot\left(\mathrm{HR}^{2}-\mathrm{BSA}\right)
$$

Where: MAP $=$ mean arterial blood pressure $(\mathrm{mmHg})$, $\mathrm{HR}=$ heart rate $(\mathrm{bpm}), \mathrm{CVP}=$ central venous pressure (estimated as $10 \%$ of MAP) $(\mathrm{mmHg}), \mathrm{BSA}=$ body surface area $\left(\mathrm{m}^{2}\right)$. Double-blind evaluation of momentary CVRI of 15 subjects ( $5 \mathrm{HI}, 10 \mathrm{HT}$ ) at time points 0,60 and 120 min during a standard heat tolerance test (HTT), which consists of a moderate excise on treadmill $\left(5 \mathrm{~km} \cdot \mathrm{h}^{-1}, 2 \%\right.$ slop) in a climatic chamber $\left(40{ }^{\circ} \mathrm{C}, 40 \%\right.$ rh) has been performed.

\section{Results}

Reduction in CVRI during exertional heat stress was observed in comparison to resting conditions in a comfortable climate (Figure 1). A significantly lower CVRI was found for the HI vis-à-vis the HT subjects ( $\mathrm{p}<$ 0.0004).

\footnotetext{
* Correspondence: Yoram.Epstein@sheba.health.gov.il

Heller Institute of Medical Research, Sheba Medical Center, Tel Hashomer,

Israel. Sackler Faculty of Medicine, Tel Aviv University, Tel Aviv, Israel.

Department of Epidemiology, Beilinson Medical Centre, Petah Tiqva, Israel
}

\section{Discussion}

Exercise-heat stress challenges the cardiovascular system, which is depicted by lower CVRI values. It follows that the efficiency of the subject's thermoregulatory mechanism can be characterized by the cardiovascular reserve. Thus, CVRI allows $\mathrm{HT}$ and $\mathrm{HI}$ individuals to be distinguished.

\section{Conclusion}

The results suggest that CVRI, assessed from non-invasive measurements, can be used as a surrogate index in HTT for determining tolerance to heat even at an early stage of the test.

Published: 14 September 2015

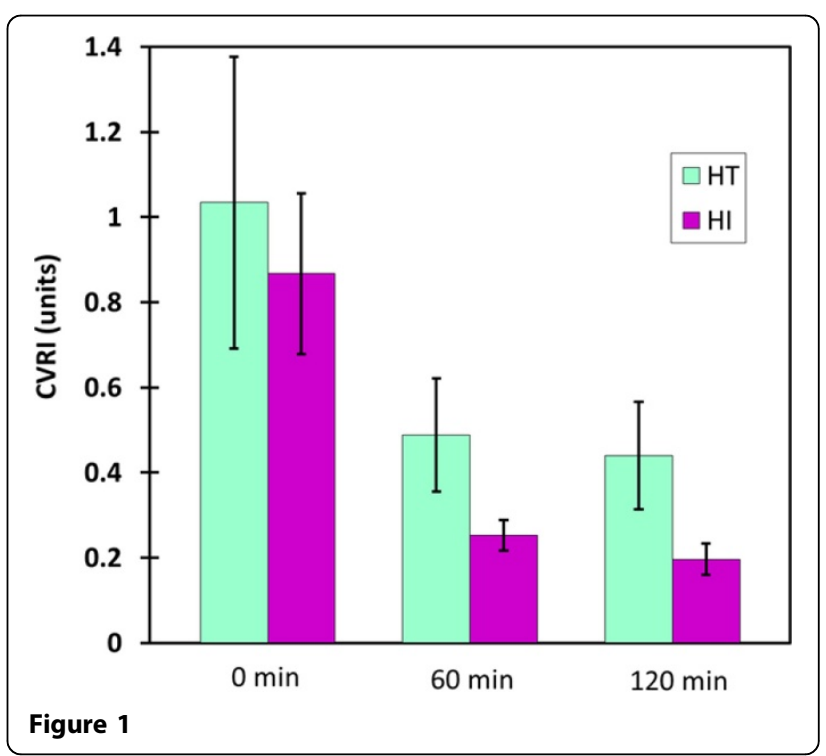




\section{Reference}

1. Gabbay U, Bobrovsky BZ: Method and system for estimating momentary cardiovascular performance reserve. U.S. Patent No. 20,150,005,647 2015.

doi:10.1186/2046-7648-4-S1-A158

Cite this article as: Epstein et al.: The cardiovascular reserve index (CVRI)

- a surrogate index in predicting heat tolerance. Extreme Physiology \&

Medicine 2015 4(Suppl 1):A158.

Submit your next manuscript to BioMed Central and take full advantage of:

- Convenient online submission

- Thorough peer review

- No space constraints or color figure charges

- Immediate publication on acceptance

- Inclusion in PubMed, CAS, Scopus and Google Scholar

- Research which is freely available for redistribution

Submit your manuscript at 